\title{
Heat and Solvent Resistant Electrospun Polybenzoxazole Nanofibers from Methoxy-Containing Polyaramide
}

\author{
Gaigai Duan, Shaohua Jiang, Shuiliang Chen, and Haoqing Hou \\ Chemistry and Chemical Engineering Department, Jiangxi Normal University, Nanchang 330022, China \\ Correspondence should be addressed to Shuiliang Chen, slchen2006@yahoo.com.cn and Haoqing Hou, haoqing@jxnu.edu.cn \\ Received 11 September 2010; Accepted 8 November 2010 \\ Academic Editor: Edward Andrew Payzant \\ Copyright () 2010 Gaigai Duan et al. This is an open access article distributed under the Creative Commons Attribution License, \\ which permits unrestricted use, distribution, and reproduction in any medium, provided the original work is properly cited.
}

Polybenzoxazole (PBO) nanofibers were prepared via electrospinning and thermal conversion from its precursor, methoxycontaining polyaramide (MeO-PA). The MeO-PA was synthesized from low-cost monomers. The structures and properties of polymers (MeO-PA and PBO) were characterized by FT-IR, TGA, DSC, OPM, SEM, and so forth. It was found that the PBO nanofibers had a diameter ranging from $300 \mathrm{~nm}$ to $350 \mathrm{~nm}$. The PBO nanofiber mats with high porosity provided a promising prospect in high-temperature filter materials, heat insulation materials, and high-temperature protection materials for its outstanding heat and solvent resistance and in preparing carbon nanofibers for its high char yield percentage.

\section{Introduction}

Aromatic polybenzoxazoles (PBOs) are a class of rigid polymers known for super thermal stability and excellent chemical resistance $[1,2]$. Traditionally, PBOs have been synthesized via high-temperature polycondensation with 4, 6-diamino-resorcinol dihydrochloride $(\mathrm{DAR} \cdot 2 \mathrm{HCl})$ and terephthalic acid or its derivatives in polyphosphoric acid (PPA) or methanesulfonic acid (MSA) [3-7]. This method involved complex monomer synthesis and purification procedures. Moreover, it is difficult to remove residual solvent MSA which was embedded in the polymers, which limited the large-scale production and application of PBOs $[1,4,8,9]$.

Using a dry-jet wet-spinning process, commercial $\mathrm{PBO}$ crude fibers with a diameter about $10-15 \mu \mathrm{m}$ were obtained $[4,7]$. However, PBO nanofibers with a diameter in the range of several hundreds nanometers were rarely reported. For the small diameter, large specific surface area, and excellent adsorption properties, nanofibers have been widely used in biomedical materials, high-temperature filters and separator materials, and high-temperature protection materials [1014]. In the last 1990s, PBO nanofibers prepared by electrospinning were mentioned by Reneker and chun [11], but there was no further report. The reason might be that $\mathrm{PBO}$ was only soluble in strong acid but was insoluble in common organic solvents. This made PBO unfavorable to directly electrospin.

In recent years, two-step thermal conversion of $\mathrm{PBO}$ from precursors, o-hydroxy polyamide or polyimide, which were synthesized by o-hydroxy aromatic diamine and aromatic dianhydride or aromatic diacid chloride, had become popular [15-17]. This method provided a simple, available, and feasible way to obtain $\mathrm{PBO}$ nanofiber by electrospinning soluble precursors of $\mathrm{PBO}$. However, the monomers of ohydroxy aromatic diamines are difficult to synthesize and led to high price, which limited the mass production of electrospun PBO nanofibers. Some previous works indicated that $\mathrm{PBO}$ can be also prepared via polycondensation and thermal conversion from much cheaper monomers of o-methoxy aromatic diamine and aromatic dianhydride or aromatic diacid chloride $[18,19]$. In this study, low-price monomers of 4, 4' -diamino-3, 3'-dimethoxydiphenyl (DMOBPA), and isophthaloyl dichloride (IPC) were selected to synthesize $\mathrm{PBO}$ precursors, methoxy-containing polyaramide (MeO$\mathrm{PA}$ ) solution. The as-synthesized $\mathrm{MeO}-\mathrm{PA}$ was electrospun into nanofibers and subsequently thermally converted into PBO nanofibers. This method offers a bright prospect for large-scale production of heat and solvent resistant $\mathrm{PBO}$ nanofibers. 
<smiles>COc1cc(-c2ccc(N)c(OC)c2)ccc1N</smiles>

DMOBPA IPC<smiles>CNC(=O)c1cccc(C(=O)Nc2ccc(-c3ccc(C#N)c(OC)c3)cc2OC)c1</smiles>

MeO-PA
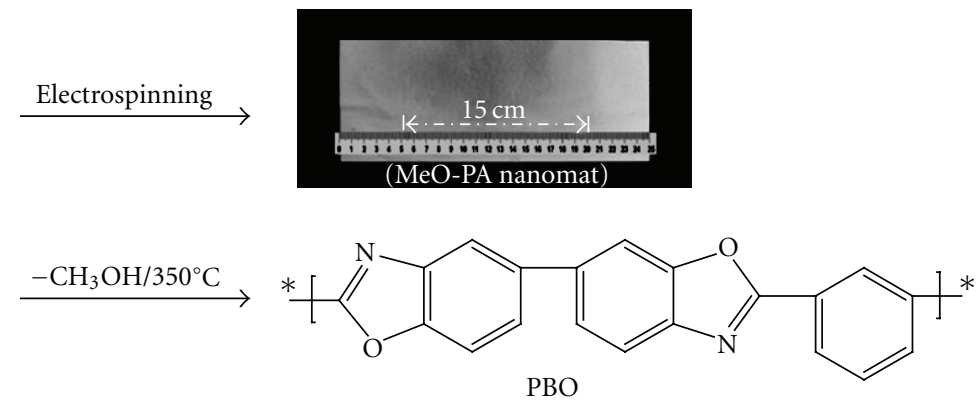

Figure 1: A schematic diagram for the preparation of electrospun PBO nanofibers.

\section{Experimental}

2.1. Materials and Measurements. IPC was purchased from Jiangxi Lianda Chemical Co., China. DMOBPA was obtained from Shanxi Beichen Daily chemical limited Co., Ltd., China. Pyridine and anhydrous lithium chloride ( $\mathrm{LiCl}$ ) were respectively supplied by Jiangsu Qiangsheng Chemical Co., China and Guangdong Shantou Xilong Chemical Co., China. N, N'-Dimethylacetamide (DMAc) was obtained from Shanghai Jingwei Chemical Co., China. IPC and DMOBPA were both purified by sublimation before use. Pyridine and DMAc were distilled under vacuum distillation, while other reagents were used as received.

Inherent viscosity was measured with Ubbelohde viscometer (Shanghai SRD Sci. Instrument Co.) on DMAc solutions of $0.5 \mathrm{~g} / \mathrm{dL}$ at $25^{\circ} \mathrm{C}$. Fourier transform infrared (FT-IR) spectrum was recorded on a Bruker tensor 27 spectrophotometer in the range of $4000-400 \mathrm{~cm}^{-1}$. Thermal Gravimetric Analysis (TGA) was carried out on a thermogravimetric analyzer WRT-3P (Shanghai) at a scan rate of $10^{\circ} \mathrm{C} / \mathrm{min}$ in flowing $\mathrm{N}_{2}(80 \mathrm{ml} / \mathrm{min})$. Differential Scanning Calorimetry (DSC) curves were obtained by NETZCHDSC $200 \mathrm{~F} 3$ at a heating rate of $10^{\circ} \mathrm{C} / \mathrm{min}$ under $\mathrm{N}_{2}$. The pictures of $\mathrm{MeO}-\mathrm{PA}$ nanomat and morphology micrographs of polymer nanofibers were taken by an Olympus FE-250 camera (8.0 mega pixels/image), a Quanta 200 scanning electron microscope (SEM), and polarizing microscope (POM) Nikon eclipse E200, respectively.

2.2. Synthesis and Fabrication of MeO-PA Nanofibers. MeOPA solution for electrospinning was prepared by polycondensation of DMOBPA and IPC in DMAc solution in the presence of pyridine and $\mathrm{LiCl}$ at $-5^{\circ} \mathrm{C}$ for $2 \mathrm{hr}$ [18], yielding a $20 \mathrm{wt} \%$ pale yellow transparent $\mathrm{MeO}-\mathrm{PA}$ solution. The inherent viscosity of the resultant $\mathrm{MeO}-\mathrm{PA}$ solution was $1.20 \mathrm{dL} / \mathrm{g}$ measured at a concentration of $0.50 \mathrm{~g} / \mathrm{dl}$ at $25^{\circ} \mathrm{C}$.

The above MeO-PA solution was diluted to a concentration of $15 \mathrm{wt} \%$ by DMAc for electrospinning, using an apparatus equipped with an electric field of $100 \mathrm{kV} / \mathrm{m}$, applying a $30 \mathrm{kV}$ electrical potential to a $30 \mathrm{~cm}$ gap between a spinneret and a metal mesh collector, at a feeding rate of $0.8 \mathrm{ml} / \mathrm{h}$, resulting in a $25 \mathrm{~cm} \times 10 \mathrm{~cm}$ nanofiber nonwoven mat. The mat was extracted in a Soxhlet with a mixed solvent of distilled water and anhydrous methanol for $48 \mathrm{hr}$ to remove the salt $\mathrm{LiCl}$, pyridinium, and the solvent DMAc and then dried in a vacuum oven at $100^{\circ} \mathrm{C}$ for $4 \mathrm{hr}$ to remove the residual solvent. Then, the resulting mat with thickness of $25 \mu \mathrm{m}$ was treated at $200^{\circ} \mathrm{C}, 330^{\circ} \mathrm{C}$, and $350^{\circ} \mathrm{C}$ under $\mathrm{N}_{2}$ atmosphere and annealed for about $2 \mathrm{hr}$ at each step. Figure 1 showed the preparation of electrospun PBO nanofibers and a photograph of $\mathrm{MeO}-\mathrm{PA}$ nanomat.

\section{Results and Discussion}

3.1. Thermal Conversion of MeO-PA Nanomats. The thermal conversion from MeO-PA nanofiber mat to $\mathrm{PBO}$ was investigated via IR spectra, thermogravimetric analysis (TGA), and differential scanning calorimetry (DSC). Figure 2 shows typical FT-IR spectra of MeO-PA treated at different temperatures. The FT-IR spectrum of $\mathrm{MeO}-\mathrm{PA}$ heated at $200^{\circ} \mathrm{C}$ for $2 \mathrm{hr}$ was found to be almost the same as that of $\mathrm{MeO}-\mathrm{PA}$ at $100^{\circ} \mathrm{C}$. The absorptions at $3422 \mathrm{~cm}^{-1}(\mathrm{~N}-\mathrm{H}$, stretching), 


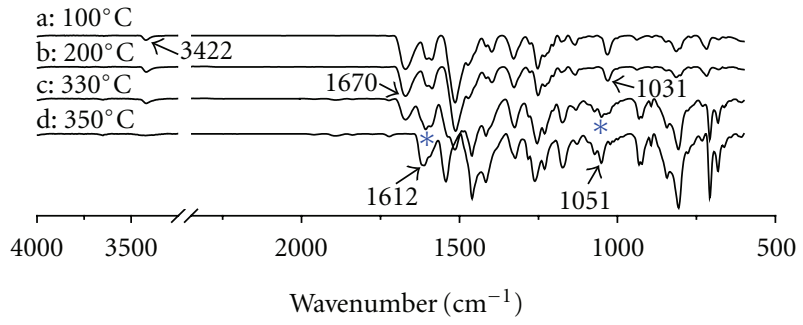

FIgure 2: FT-IR spectra of MeO-PA with different treating temperatures.

$1670 \mathrm{~cm}^{-1}$ (C=O, stretching), $1598 \mathrm{~cm}^{-1}(\mathrm{~N}-\mathrm{H}$, bending, $\mathrm{C}-$ $\mathrm{N}$, stretching), and $1031 \mathrm{~cm}^{-1}\left(\mathrm{Ar}-\mathrm{O}-\mathrm{CH}_{3}\right.$, stretching) still remained, and no sign of benzoxazole ring could be found at all, which indicated that the thermal conversion of $\mathrm{PBO}$ did not occur when the PA mat was heated to $200^{\circ} \mathrm{C}$. As the temperature increased to $350^{\circ} \mathrm{C}$, absorption peaks at $1612 \mathrm{~cm}^{-1}\left(^{*}\right)$ and $1051 \mathrm{~cm}^{-1}\left(^{*}\right)$ gradually increased, which provided an evidence of the formation of polybenzoxazole ring [15-17]. The thermal conversion from $\mathrm{MeO}-\mathrm{PA}$ mat to $\mathrm{PBO}$ was carried out completely at $350^{\circ} \mathrm{C}$, as proven by the disappearance of characteristic amide carbonyl peaks at $1670 \mathrm{~cm}^{-1}, 3422 \mathrm{~cm}^{-1}\left(\mathrm{~N}-\mathrm{H}\right.$, stretching), $1600 \mathrm{~cm}^{-1}$, and $1031 \mathrm{~cm}^{-1}$ and the appearance of characteristic benzoxazole ring absorptions at $1612 \mathrm{~cm}^{-1}, 1051 \mathrm{~cm}^{-1}$, which confirmed that the aramide group reacted with the methoxyl group and formed benzoxazole ring.

The TGA curves of $\mathrm{MeO}-\mathrm{PA}$ samples treated at $200^{\circ} \mathrm{C}$ and $350^{\circ} \mathrm{C}$ provided additional information about the thermal conversion of MeO-PA mat as shown in Figure 3. TGA trace of MeO-PA $\left(200^{\circ} \mathrm{C}\right)$ revealed two distinct weight-loss steps of thermal conversion. The first step, occurring between about $250^{\circ} \mathrm{C}$ and $420^{\circ} \mathrm{C}$, was attributed to the intramolecular cyclization of the neighboring groups of $-\mathrm{OCH}_{3}$ and NHCO - on the benzene ring to form oxazole ring and corresponded to a weight loss of $21.5 \%$, which matched up the theoretical mass loss occurring upon the loss of $2 \mathrm{~mol}$ of $\mathrm{CH}_{3} \mathrm{OH}$ per unit of $20.31 \%$. The second step, started at about $600^{\circ} \mathrm{C}$, could be attributed to the decomposition of PBO. DSC trace (Figure 4) of MeO-PA (a) exhibited a strong exothermic process from $300^{\circ} \mathrm{C}$ and $400^{\circ} \mathrm{C}$ that was attributed to the loss of $\mathrm{CH}_{3} \mathrm{OH}$ during the formation of oxazole ring, whereas no significant heat changes in another trace of sample (b) implied a completely conversion to $\mathrm{PBO}$ when $\mathrm{MeO}-\mathrm{PA}$ mat were heated at $350^{\circ} \mathrm{C}$ for $2 \mathrm{hr}$.

The above results from FT-IR, TGA, and DSC curves were correspondent with each other and provided clear evidence that the $\mathrm{MeO}-\mathrm{PA}$ mat was converted to $\mathrm{PBO}$ when heated at $350^{\circ} \mathrm{C}$, which was $150^{\circ} \mathrm{C}$ lower than the converting temperature of hydroxyl- or methoxy-containing polyimide $[15,17,19]$.

3.2. Morphology of Polymer Nanofibers. MeO-PA nanofibers were prepared by electrospinning of a $15 \mathrm{wt} \%$ solution of MeO-PA and collected onto a metal mesh, imposing a $30 \mathrm{kV}$ electrical potential at a feeding rate of $0.8 \mathrm{ml} / \mathrm{h}$.

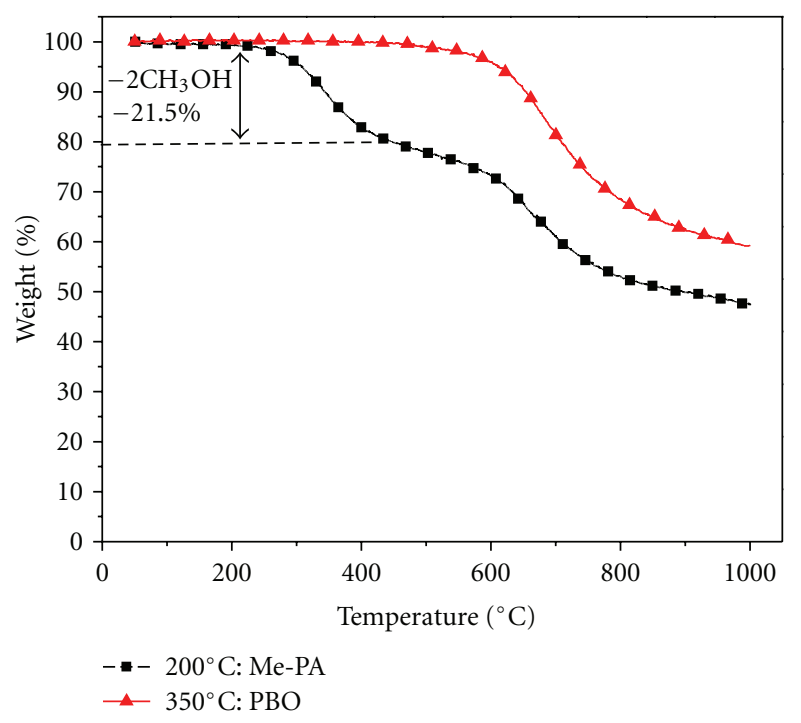

Figure 3: TGA curves of $\mathrm{MeO}-\mathrm{PA}$ treated at $200^{\circ} \mathrm{C}$ and $350^{\circ} \mathrm{C}$ at a heating rate of $10^{\circ} \mathrm{C} / \mathrm{min}$ in $\mathrm{N}_{2}$.

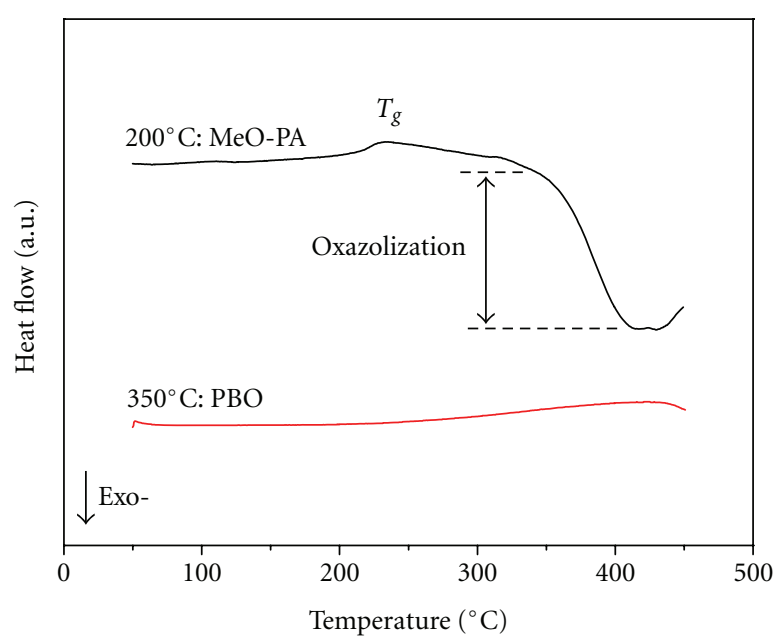

Figure 4: DSC curves of MeO-PA treated at $200^{\circ} \mathrm{C}$ and $350^{\circ} \mathrm{C}$ at a heating rate of $10^{\circ} \mathrm{C} / \mathrm{min}$ in $\mathrm{N}_{2}$.

PBO nanofibers were obtained by heating treatment of $\mathrm{MeO}-\mathrm{PA}$ nanofibers at $350^{\circ} \mathrm{C}$ for $2 \mathrm{hr}$. The SEM images of collected nanofibers are shown in Figure 5. Fibers were uniform with a centralized diameter distribution of 300$350 \mathrm{~nm}$ in images (a), (b) and (c), (d). More coiled fibers stacking could be seen in (a) than in (c) because $\mathrm{MeO}$ PA has more flexible molecule configuration than that of the rigid rod-like benzoxazole molecule. What is more, the nanopores with a size distribution of several nanometers to several micrometers were formed both in $\mathrm{MeO}-\mathrm{PA}$ and $\mathrm{PBO}$ nanomats by electrospinning, which was favorable to fabricate microfiltration or nanofiltration materials [20].

3.3. Thermal Properties of Polymer Nanofiber Mats. The thermal properties of $\mathrm{MeO}-\mathrm{PA}$ and $\mathrm{PBO}$ nanomats in $\mathrm{N}_{2}$ atmosphere were characterized by TGA and DSC. 


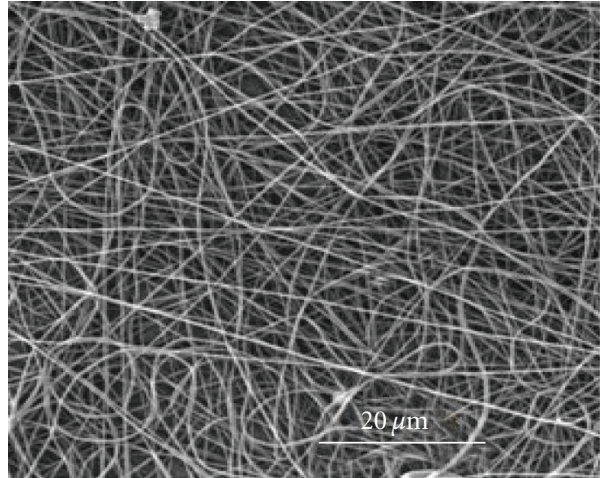

(a)

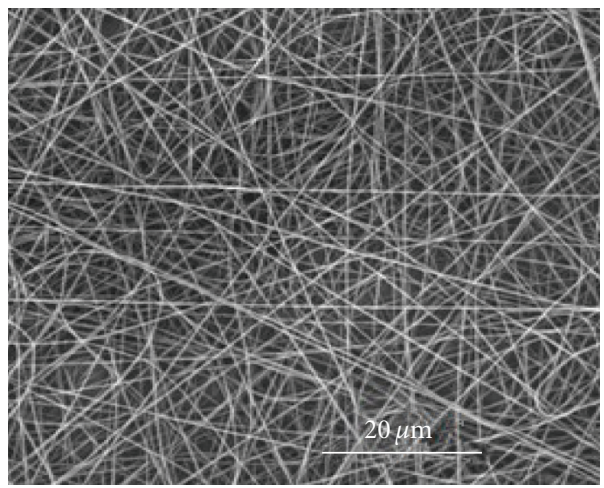

(c)

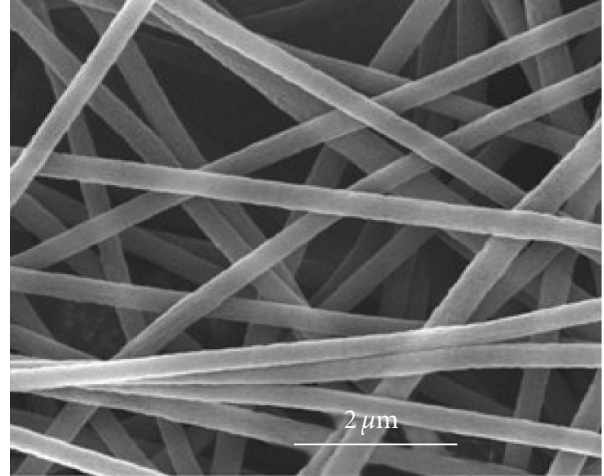

(b)

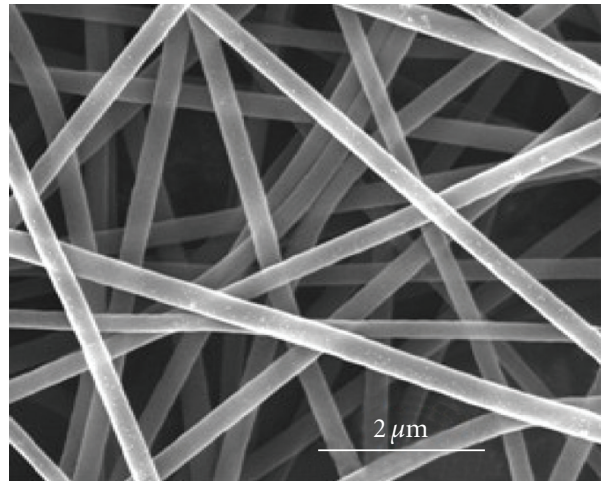

(d)

FIGURE 5: SEM images of polymer nanofibers. (a) and (b): MeO-PA nanofibers; (c) and (d): PBO nanofibers.

TABle 1: Prices comparison of o-hydroxy aromatic diamines and DMOBPA.

\begin{tabular}{lcccc}
\hline Name abbr. & CSA number & Company & Purity & Price $(\$ / 25 \mathrm{~g})$ \\
\hline IPC & $99-63-8$ & TCI & $99.0 \%$ & 26.0 \\
DAR·2HCl & $16523-31-2$ & TCI & $98.0 \%$ & 483.8 \\
DHB & $2373-98-0$ & TCI & $98.0 \%$ & 366.2 \\
BisAPAF & $83558-87-6$ & TCI & $98.0 \%$ & 270.6 \\
DMOBPA & $119-90-4$ & Alfa Aesar & $98.0 \%$ & 105.9 \\
& & TCI & $95.0 \%$ & 42.01 \\
\hline
\end{tabular}

As shown in Figure 3, TGA curves of MeO-PA nanofiber mat revealed that weight loss started around $200^{\circ} \mathrm{C}$ due to the thermal conversion while that of $\mathrm{PBO}$ nanomat exhibited firstly decomposition around $500^{\circ} \mathrm{C}$ for the stable and rigid rod-like molecule structure. The 5\% weight-loss temperature $\left(T_{5}\right), 10 \%$ weight-loss temperature $\left(T_{10}\right)$, and char yield percentage at $1000^{\circ} \mathrm{C}$ of $\mathrm{MeO}-\mathrm{PA}$ and $\mathrm{PBO}$ are summarized in Table 2. The $T_{5}$ and $T_{10}$ values of $\mathrm{PBO}$ were $611^{\circ} \mathrm{C}$ and $654^{\circ} \mathrm{C}$, respectively, which were higher than that of i-BPDA-MPD-PI with similar molecule structure [21]. This clearly indicates that the thermal stability of $\mathrm{PBO}$ nanofiber mat in an inert nitrogen atmosphere was much higher than that of PIs. In addition, the char yield of $\mathrm{PBO}$ nanofiber mat was as high as $59.3 \%$ at $1000^{\circ} \mathrm{C}$, which was even higher than the char yield of PMDA-DMB-PI
TABLE 2: Thermal properties of different polymers.

\begin{tabular}{lcccc}
\hline Sample & $T_{\mathrm{g}}^{\mathrm{a}}\left({ }^{\circ} \mathrm{C}\right)$ & $T_{5 \%}^{\mathrm{b}}\left({ }^{\circ} \mathrm{C}\right)$ & $T_{10 \%}^{\mathrm{b}}\left({ }^{\circ} \mathrm{C}\right)$ & Char yield $(\%)$ \\
\hline MeO-PA nanomat & 228 & 305 & 342 & $47.6^{\mathrm{c}}$ \\
PBO nanomat & $\mathrm{ND}$ & 611 & 654 & $59.3^{\mathrm{c}}$ \\
i-BPDA-MPD-PI ${ }^{21}$ & - & 552 & - & - \\
PMDA-DMB-PI 22 & 341.6 & 500 & 581 & $51.0^{\mathrm{d}}$ \\
\hline${ }^{\mathrm{a}}$ : Glass transition temperature detected by DSC; ND: none detected; \\
b: 5\% and 10\% weight loss temperature recorded by TGA; \\
c: char yield percentage $(\%)$ at $1000^{\circ} \mathrm{C}$ in $\mathrm{N}_{2} ;$ \\
d: char yield $(\%)$ at $800^{\circ} \mathrm{C}$ in $\mathrm{N}_{2}$.
\end{tabular}

at $800^{\circ} \mathrm{C}$ [22]. Therefore, this kind of $\mathrm{PBO}$ nanofiber mat might become a prospective precursor material for carbon nanofibers.

3.4. Solubility Properties of Polymer Nanofiber Mats. The solubility behavior of $\mathrm{MeO}-\mathrm{PA}$ and $\mathrm{PBO}$ nanofiber mats was tested in different kinds of solvents, and the results are summarized in Table 3. MeO-PA nanomats were soluble in CSA, MSA, DMAc, and DMF with addition of $\mathrm{LiCl}$, soluble in DMSO and NMP while heating, while insoluble in nonpolar solvents, such as ethyl ether, chloroform. But, PBO nanomats showed an excellent solvent-resistant property. Except for strong acids, such as MSA and CSA, PBO nanomats were insoluble in any organic solvents due to the existence of rigid rod-like segment in polymer backbones. 
TABLE 3: Solubility behavior of MeO-PA and PBO nanomats.

\begin{tabular}{lcccccccc}
\hline Sample & DMAc & DMF & CSA & DMSO & MSA & Ethyl ether & Chloroform & NMP \\
\hline $\mathrm{MeO}-\mathrm{PA}$ & +- & +- & ++ & $+\mathrm{h}$ & ++ & -- & -- & $+\mathrm{h}$ \\
$\mathrm{PBO}$ & -- & -- & ++ & -- & ++ & -- & -- & -- \\
\hline
\end{tabular}

++ : soluble at room temperature; +h: soluble on heating; +-: soluble by adding LiCl; - -: insoluble; CSA: concentrated sulfuric acid; MSA: methyanesulfonic acid.

\section{Conclusions}

PBO nanomats were prepared from monomers DMOBPA and IPC by polycondensation, electrospinning, and thermal conversion. The $\mathrm{PBO}$ nanofiber had diameter ranging from $300 \mathrm{~nm}$ to $350 \mathrm{~nm}$. The resulting PBO nanomat with an initial decomposition temperature of $500^{\circ} \mathrm{C}$ and $5 \%$ weight loss temperature up to $611^{\circ} \mathrm{C}$ contained many nanopores with a size distribution of several nanometers to several micrometers, and it was quite insoluble in organic solvents. Due to the use of low-cost monomers, electrospun PBO nanofiber mats by this method provided a bright prospect for large-scale production of heat and solvent resistant PBO nanofibers.

\section{References}

[1] J. F. Wolfe, Encyclopedia of Polymer Science and Engineering, Wiley, New York, NY, USA, 1985.

[2] D. E. Cassidy, Thermally Stable Polymers, Marcel Dekker, New York, NY, USA, 1979.

[3] J. F. Wolfe and F. E. Arnold, "Rigid-rod polymers. 1. Synthesis and thermal properties of para-aromatic polymers with 2,6benzobisoxazole units in the main chain," Macromolecules, vol. 14, no. 4, pp. 909-915, 1981.

[4] E. W. Chow and S. N. Kim, "Synthesis, spinning, and fiber mechanical properties of poly(p-phenylenebenzobisoxazole)," Macromolecules, vol. 14, no. 4, pp. 920-924, 1981.

[5] J. F. Wolfe, B. H. Loo, and F. E. Arnold, "Rigid-rod polymers. 2. Synthesis and thermal properties of para-aromatic polymers with 2,6-benzobisthiazole units in the main chain," Macromolecules, vol. 14, no. 4, pp. 915-920, 1981.

[6] M. Ueda, H. Sugita, and M. Sato, "Synthesis of poly(benzoxazole(s by direct polycondensation of dicarboxylic acids with 3,3'-dihydroxybenzidine dihydrochloride using phosphorus pentoxide/methanesulfonce acid as condensing agent and solvent," Journal of Polymer Science: Polymer Chemistry, vol. 24, pp. 1019-1011, 1986.

[7] J. M. Jiang, H. J. Zhu, G. Li, J. H. Jin, and S. L. Yang, "Poly(p-phenylene benzoxazole) fiber chemically modified by the incorporation of sulfonate groups," Journal of Applied Polymer Science, vol. 109, no. 5, pp. 3133-3139, 2008.

[8] Dow Chemical Co. U.S. Patent no. 5410083, 1995.

[9] Dow Chemical Co. U.S. Patent no. 5414130, 1995.

[10] N. Bhardwaj and S. C. Kundu, "Electrospinning: a fascinating fiber fabrication technique," Biotechnology Advances, vol. 28, no. 3, pp. 325-347, 2010.

[11] D. H. Reneker and I. Chun, "Nanometre diameter fibres of polymer, produced by electrospinning," Nanotechnology, vol. 7, no. 3, pp. 216-223, 1996.

[12] A. Greiner and J. H. Wendorff, "Electrospinning: a fascinating method for the preparation of ultrathin fibers," Angewandte Chemie-International Edition, vol. 46, no. 30, pp. 5670-5703, 2007.
[13] N. Vitchuli, Q. Shi, J. Nowak, M. McCord, M. Bourham, and $\mathrm{X}$. Zhang, "Electrospun ultrathin nylon fibers for protective applications," Journal of Applied Polymer Science, vol. 116, no. 4, pp. 2181-2187, 2010.

[14] X.-H. Qin and S.-Y. Wang, "Filtration properties of electrospinning nanofibers," Journal of Applied Polymer Science, vol. 102, no. 2, pp. 1285-1290, 2006.

[15] G. L. Tullos and L. J. Mathias, "Unexpected thermal conversion of hydroxy-containing polyimides to polybenzoxazoles," Polymer, vol. 40, no. 12, pp. 3463-3468, 1999.

[16] T.-K. Kim, K.-Y. Choi, K.-S. Lee, D.-W. Park, and M. Y. Jin, "Thermal conversion of t-butyloxycarbonyloxy attached polyamides to polybenzoxazoles," Polymer Bulletin, vol. 44, no. 1, pp. 55-62, 2000.

[17] G. L. Tullos, J. M. Powers, S. J. Jeskey, and L. J. Mathias, “Thermal conversion of hydroxy-containing imides to benzoxazoles: polymer and model compound study," Macromolecules, vol. 32, no. 11, pp. 3598-3612, 1999.

[18] E. S. Yoo, A. J. Gavrin, R. J. Farris, and E. B. Coughlin, "Synthesis and characterization of the polyhydroxyamide/polymethoxyamide family of polymers," High Performance Polymers, vol. 15, no. 4, pp. 519-535, 2003.

[19] Y. Gao, M. G. Zhang, L. Z. Yuan, F. Wang, B. X. Wang, and J. J. Shen, "Preparation and Heat Resistance of Poly(biphenylenepyromellitimide)s," Nanjing Normal University (Nature Science), vol. 28, pp. 69-74, 2005.

[20] M. G. McKee, J. M. Layman, M. P. Cashion, and T. E. Long, "Phospholipid nonwoven electrospun membranes," Science, vol. 311, no. 5759, pp. 353-355, 2006.

[21] I. Rozhanskii, K. Okuyama, and K. Goto, "Synthesis and properties of polyimides derived from isomeric biphenyltetracarboxylic dianhydrides," Polymer, vol. 41, no. 19, pp. 70577065, 2000.

[22] E. Ekinci, S. Köytepe, A. Paşahan, and T. Seçkin, "Preparation and characterization of an aromatic polyimide and its use as a selective membrane for $\mathrm{H} 2 \mathrm{O} 2$," Turkish Journal of Chemistry, vol. 30, no. 3, pp. 277-285, 2006. 

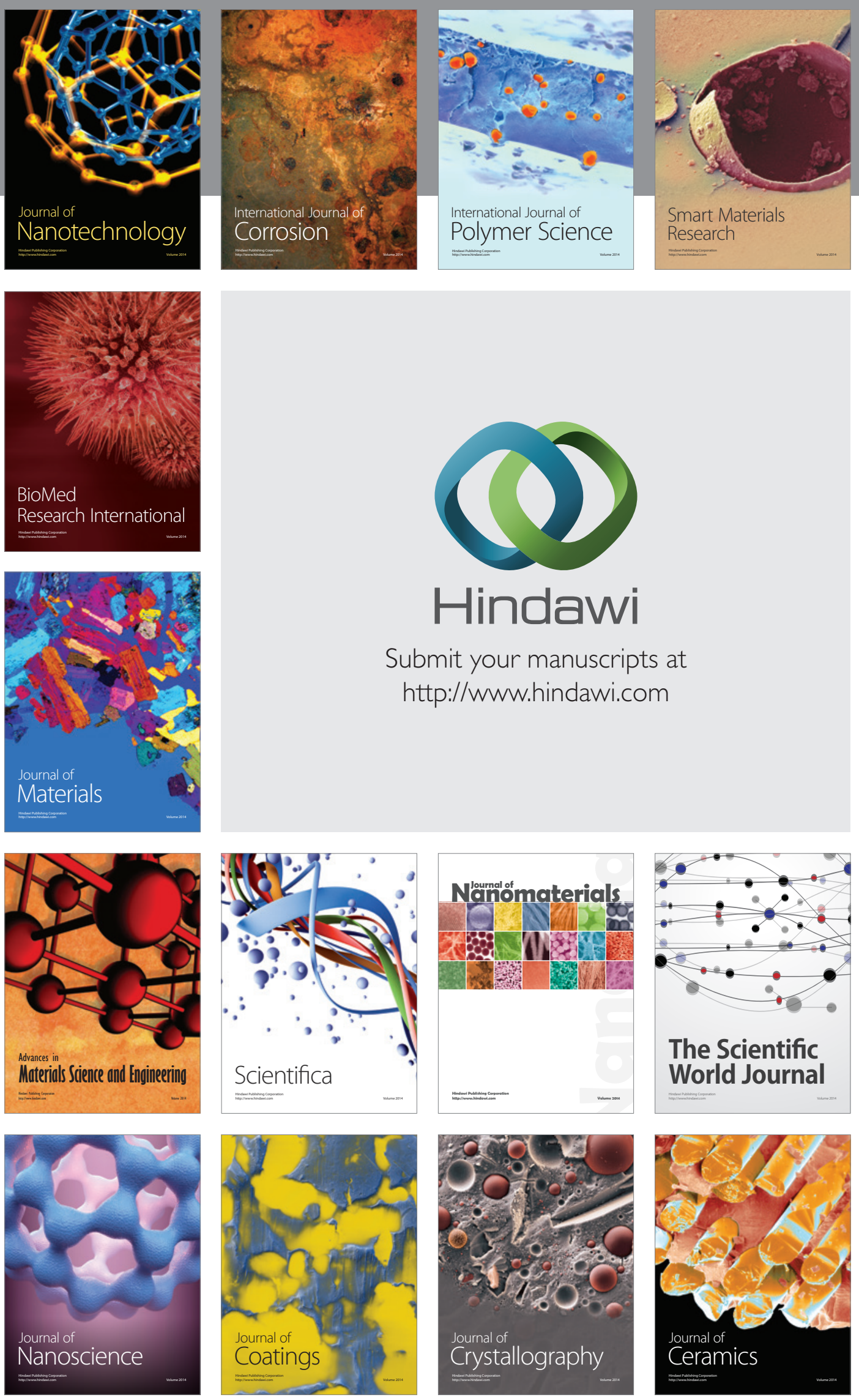

The Scientific World Journal

Submit your manuscripts at

http://www.hindawi.com

\section{World Journal}

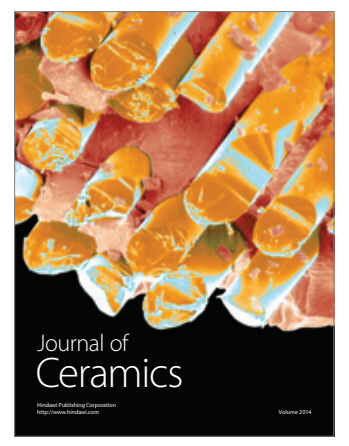

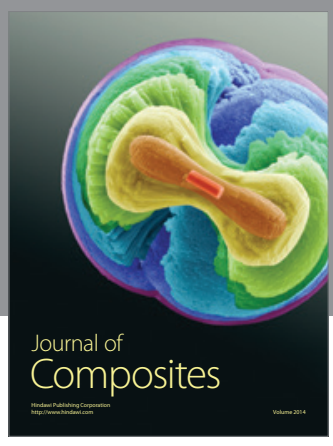
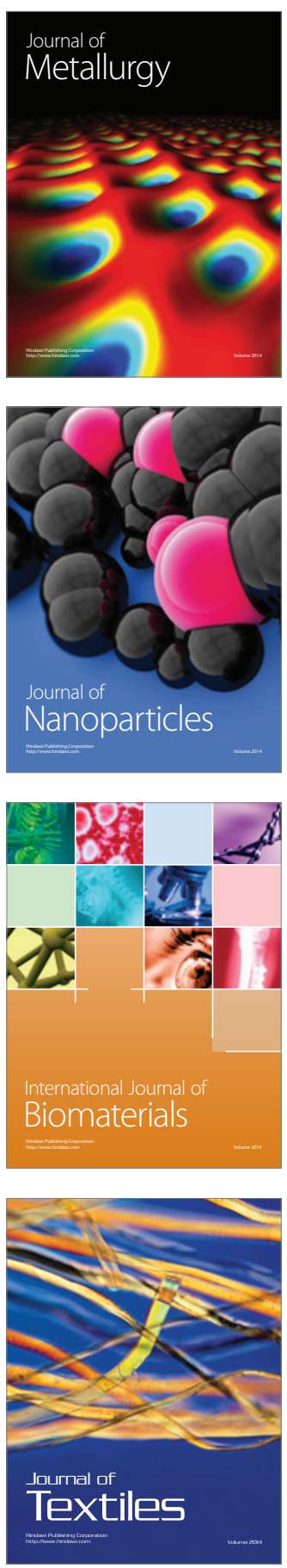